\title{
Novel agents and biomarkers for acute lymphoid leukemia
}

\author{
Yanmin Zhao, He Huang and Guoging Wei*
}

\begin{abstract}
New genetic markers for adult acute lymphoblastic leukemia (ALL) have been found to have prognostic impact, such as the lymphoid transcription factor gene IKZF1 alterations, which are associated with a high rate of leukemic relapse in B-ALL. Although complete remission rates by induction chemotherapy in ALL are now high, the long-term survival is still disappointing. Improvements in the survival outcome of ALL have been observed in young adults as a result of the use of pediatric inspired regimens and the broadening of the number of patients who are eligible for allogeneic SCT. Development of new and less toxic agents also provide promise to improve the outcome in adult $A L L$, such as tyrosine kinase inhibitors in Ph-positive ALL, rituximab in CD20-positive disease, blinatumomab in precursor B-ALL and nelarabine in T-lineage ALL. Challenges for the future are to implement genomic profiling into the clinical setting to guide risk stratification and providing novel targets for tailored therapies.
\end{abstract}

Keywords: Acute lymphoblastic leukemia, Genetic alteration, Philadelphia chromosome, Tyrosine kinase inhibitor, Monoclonal antibodies, Stem cell transplantation

\section{Introduction}

Acute lymphoblastic leukemia (ALL) is a biologically and clinically heterogeneous neoplasm of lymphoid progenitors, with approximately $85 \%$ of cases being of B-cell lineage and 15\% of T-cell lineage. In contrast to childhood ALL, in whom approximately $90 \%$ are now cured [1], adults with ALL usually carry a worse prognosis with a long-term survival rate less than $35-40 \%$ [2], even with allogeneic hematopoietic stem cell transplantation (allo$\mathrm{SCT}$ ). The current understanding of the biologic determinants of treatment failure in ALL is limited, and the treatment of refractory or relapsed ALL remains a major challenge. By summarizing recent dvelopments and particularly the highlights from the 2012 ASH Annual Meeting, this study will review some latest advances in the biological features of adult ALL, with an emphasis on the role of genetic alteration on prognosis of this malignancy and treatment approaches to both Philadelphia chromosomepositive $(\mathrm{Ph}+)$ and negative (Ph-) ALL.

\footnotetext{
* Correspondence: weiguoging2000@hotmail.com

Bone Marrow Transplantation Center, The First Affiliated Hospital of Zhejiang University, No. 79 Qing Chun Rd, Hangzhou 310003, China
}

\section{Integration of genetic markers into risk stratification} algorithms

The inherent heterogeneity of ALL requires an accurate assessment of risk to aid treatment decisions. In the past, the classic prognostic factors were age, presenting white blood cell (WBC) counts, cytogenetic abnormalities and upfront response to induction therapy. One of the strongest adverse prognostic features is the presence of the $\mathrm{Ph}$ chromosome $t(9 ; 22)$. Recently, a retrospective analysis of the Mayo Clinic leukemia database has identified high risk cytogenetics $[-7, \operatorname{del}(7 \mathrm{p}),+8$, MLL translocations, $\mathrm{t}(1 ; 19)$, $\mathrm{t}(17 ; 19), \mathrm{t}(5 ; 14)]$, very high risk cytogenetics categories [t(4;11), t $(8 ; 14)$, complex ( $\geq 5$ abnormalities), hypodiploidy, triploidy] [3], low platelet counts and poor Performance Status (PS) at diagnosis were independent predictors of inferior outcomes in patients with Ph-negative ALL [4]. Detection of minimal residual disease (MRD) is also used to identify high-risk patients [5]. These prognostic clinical features of ALL were summarized here in Table 1.

Nowadays, microarrays and next generation sequencing provide new approaches to profile ALL genomes. These studies have identified some new subtypes of ALL harboring recurring submicroscopic genetic alterations, several of which have clear implications for risk stratification and targeted therapeutic intervention.

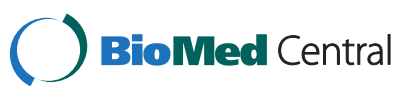


Table 1 Prognostic clinical features of ALL

\begin{tabular}{ll}
\hline Risk factors & Prognosis association \\
\hline At presentation & \\
Age & Adverse outcome with advancing age \\
CNS involvement & Adverse outcome \\
Presenting WBC count & Adverse for B-ALL $>30$ \\
& Adverse for T-ALL $>100$ \\
ECOG PS & Poor PS at diagnosis were an independent \\
& predictor of inferior outcomes \\
Cytogenetics & Favorable: hyperdiploidy \\
& Adverse: $t(9 ; 22), t(4 ; 11), t(8 ; 14)$, complex \\
& $(\geq 5$ abnormalities), hypodiploidy, triploidy, \\
& -7, del(7p), $+8, M L L$ translocations, $t(1 ; 19)$, \\
& $t(17 ; 19), t(5 ; 14)]$ \\
In response to therapy & \\
Time to initial response & Adverse: failure to attain complete remission \\
& within 4 weeks of induction \\
Detection of MRD & $\begin{array}{l}\text { Adverse: detection at various time-specific } \\
\text { points in several studies }\end{array}$ \\
\hline
\end{tabular}

Till now, more than 50 recurring genetic alterations have been identified, and many of the genes involved encode proteins with key roles in lymphoid development (PAX5, IKZF1, and EBF1), transcriptional regulation (ETV6, ERG), lymphoid signaling (BTLA, CD200, TOX, BLNK, VPREB1), cell-cycle regulation and tumor suppression (CDKN2A/ CDKN2B, RB1, PTEN), and drug responsiveness (the glucocorticoid receptor NR3C1) [6]. These specific genetic alterations cooperate in leukemogenesis, however, few have been found to have definite prognostic impact, with the notable exception of alterations of the lymphoid transcription factor gene IKZF1 in B-ALL.

IKZF1 encodes IKAROS, a zinc finger transcription factor that is required for the development of all lymphoid lineages [7]. During the last 5 years, IKZF1 has been identified as one of the most clinically relevant tumor suppressors in ALL $[8,9]$. Deletion or sequence mutation of IKZF1 are detected in more than $70 \%$ of BCR-ABL1+ lymphoid leukemia, including de novo ALL and chronic myeloid leukemia at progression to lymphoid blast crisis, [10] and are associated with poor outcome in BCR-ABL1+ adult ALL [11]. Moreover, a subset of BCR-ABL1 negative B-ALL patients with IKZF1 alterations exhibit a geneexpression profile similar to BCR-ABL1+ ALL, named as BCR-ABL1-like ALL. These cases may have alternative genetic events resulting in aberrant activation of tyrosine kinase signaling pathways similar to those downstream of BCR-ABL1, including rearrangement of CRLF2 and activating mutations of Janus kinases (JAK1/2) [12,13]. The prognosis of BCR-ABL1-like ALL is poor. In the COG AALL0232 study of high-risk B-progenitor ALL, the event-free survival (EFS) for BCR-ABL1-like cases was $62.6 \% \pm 6.9 \%$ compared with $85.8 \% \pm 2.0 \%$ for non-
BCR-ABL1-like cases $(\mathrm{P}<0.0001)$ and was associated with poor outcome after adjustment for age, sex, WBC at presentation, and levels of MRD [14].

In addition to IKZF1, other genetic alterations were also identified to have some prognostic impact on ALL and incorporated into risk stratification algorithms (Table 2). For example, B-ALL cases with CRLF2 rearrangements, JAK1/2 mutations [12], CDKN2A/B deletions [15], TP53 deletions/mutations [16], or CREBBP deletions/mutations [17] had inferior outcomes in terms of response to chemotherapy, overall survival, or incidence of relapse. For adult T-ALL, NOTCH1 and/or FBXW7 (N/F) mutations were associated with a favorable outcome $[18,19]$, while N/KRAS mutations or PTEN deletions/mutations demonstrated trends to a worse outcome [20,21]. Therefore, Trinquand A et al. propose a new T-ALL oncogenetic classifier defining low-risk patients as those with N/F mutation but no RAS/PTEN mutation, allowing identification of nearly $50 \%$ very good prognosis T-ALL adults [21]. Recently, mutations in the cytosolic 5 '-nucleotidase II gene (NT5C2), were identified to drive resistance to treatment with nucleoside analog therapies in $\mathrm{T}$ cell or B-precursor ALL [22].

\section{Current treatment options for treatment of Ph-positive acute lymphoblastic leukemia}

Philadelphia chromosome/BCR-ABL-positive ALL has long been recognized as a high-risk subset of adult ALL with the most unfavorable prognosis. Published data show a disappointing long-term survival of $20 \%$ or less with chemotherapy alone [23]. Introduction of the tyrosine kinase inhibitors (TKIs), most commonly imatinib (IM) in combination chemotherapy has led to an encouraging treatment outcome, [24-28] with complete remission rates exceeding $90 \%$ and estimated overall survival (OS) ranging from $30 \%$ to $70 \%$. The proportion of patients able to proceed to and benefit from allo-SCT in CR1 has increased with TKI-based therapy, and there is no evidence that IM has an adverse effect on transplant-related morbidity or mortality. Nevertheless, there are still many challenges related to this disease, including the selection of appropriate pre-transplant therapy, the correct use of TKIs after transplant, and development of potential therapeutic strategies to overcome disease resistance. Furthermore, the incidence of $\mathrm{Ph}+\mathrm{ALL}$ increases with age, and a significant proportion of elderly patients are not eligible for SCT, in whom alternative approaches should be explored.

\section{Therapeutic strategies for 'transplantable age' patients}

It is well established that TKI-based treatment, followed by allo-SCT in CR1, is the gold standard therapy and provides curative potential for adults with Ph + ALL. Studies from several cooperative groups, have showed 3-year 
Table 2 Novel key genomic alteration associated with prognosis in adult ALL

\begin{tabular}{|c|c|c|}
\hline Gene alteration & Frequency & Comments \\
\hline IKZF1 deletions and sequence mutations & $\begin{array}{l}15 \% \text { of pediatric B-ALL cases; } 70 \% \text { of } \\
\text { BCR-ABL1 + lymphoid leukemia, and } \\
30 \% \text { of high-risk BCR-ABL1-like B-ALL }\end{array}$ & $\begin{array}{l}\text { IKZF1 alterations are associated with poor outcome in both BCR-ABL1-positive and } \\
\text { negative ALL cases, and triple the risk of treatment failure. IKZF1 status is an independent } \\
\text { risk factor at a multivariable analysis of established prognostic factors. }\end{array}$ \\
\hline CRLF2 rearrangement (as IGH@-CRLF2 or P2RY8-CRLF2) & $\begin{array}{l}\text { Up to } 16 \% \text { of pediatric and adult B-ALL; } \\
>50 \% \text { Down syndrome (DS) ALL }\end{array}$ & $\begin{array}{l}\text { Concomitant JAK1/2 mutations in }>50 \% \text { of cases; associated with IKZF1 alteration and } \\
\text { poor outcome, particularly in non-DS-ALL. }\end{array}$ \\
\hline JAK1/2 mutations & $\begin{array}{l}\text { Up to } 10 \% \text { of high-risk BCR ABL1-like B-ALL; } \\
18-35 \% \text { of DS ALL }\end{array}$ & $\begin{array}{l}\text { Almost all cases of B-ALL with JAK1/2 mutations harbor concomitant CRLF2 rearrangement, } \\
\text { associated with poor outcome; may be responsive to JAK inhibitors. }\end{array}$ \\
\hline CREBBP deletions and sequence mutations & $19 \%$ of relapsed B-ALL & $\begin{array}{l}\text { Associated with glucocorticoid resistance; Resulted in impaired acetylation of histone } \\
\text { targets; histone deacetylase inhibitors may be useful. }\end{array}$ \\
\hline CDKN2A/B deletions & $\sim 30 \%$ of B-ALL; $47 \%$ of relapsed BCR-ABL1-ALL; & $\begin{array}{l}\text { Associated with poor outcome in terms of overall survival, and incidence of relapse in } \\
\text { adult BCR-ABL1-positive ALL; controversial prognosis in other B-ALL subtypes. }\end{array}$ \\
\hline TP53 deletions and sequence mutations & Up to $12 \%$ of $B-A L L ;$ & $\begin{array}{l}\text { Enriched at relapse and associated with non-response to chemotherapy and poor } \\
\text { event-free survival and overall survival. }\end{array}$ \\
\hline PHF6 deletions and sequence mutations & $38 \%$ of adult T-ALL cases & Associated with reduced overall survival. \\
\hline PTEN deletions and sequence mutations & $6-8 \%$ of $\mathrm{T}-\mathrm{ALL}$ & $\begin{array}{l}\text { Associated with poor response to chemotherapy and resistance to pharmacological } \\
\text { inhibition } \\
\text { of NOTCH1 }\end{array}$ \\
\hline N/K-RASmutations & $10 \%$ of adult T-ALL & N/K-RASmutations demonstrated trends to a worse outcome. \\
\hline NOTCH1 mutations & $\sim 50 \%$ of T-ALL & Associated with favorable outcome \\
\hline FBXW7 mutations & $12-24 \%$ of adult T-ALL & $\begin{array}{l}\text { Associated with favorable prognosis due to enhanced glucocorticoid receptor a levels } \\
\text { and steroid sensitivity }\end{array}$ \\
\hline NT5C2 mutations & $\begin{array}{l}\text { 19\% of relapse T cell ALL and 3\% of relapse } \\
\text { B-precursor ALL }\end{array}$ & $\begin{array}{l}\text { NT5C2 mutant proteins increase nucleotidase activity in vitro and drive resistance to } \\
\text { treatment with nucleoside analog therapies }\end{array}$ \\
\hline
\end{tabular}


survival probabilities of $55-70 \%$ in young adults receiving IM-containing induction followed by myeloablative allo-SCT $[27,28]$. And the survival is inferior in nontransplanted patients, despite the inclusion of IM in the protocols. More recently, the Northern Italy Leukemia Group disclosed a long term results of patients who were treated with chemotherapy plus short IM pulses. In the study, the probability to receive an SCT was significantly increased in IM + patients compared with IM- cohort ( $63 \%$ vs. $39 \%, \mathrm{p}=0.04)$, indicating that incorporation of IM to chemotherapy not only increase the CR rate, but also increase the number of patients proceeding to SCT. And patients receiving a SCT had the best outcome ( $\mathrm{n}=58 ; 5$-years OS $49 \%)$, while in those unable to reach SCT, outcome was inferior $(\mathrm{IM}+\mathrm{SCT}-\mathrm{n}=17$, 5-years OS 11\%; IM-SCT-: $\mathrm{n}=13$, 5-years OS 8\%), indicating allo-SCT remain the best consolidation option even in patients who achieve a good response to TKIbased therapy [29].

Of note, there is increasing reluctance to offer allo-SCT to younger patients in the TKI era, because younger individuals usually have a better outcome to chemotherapy/ TKI alone and have more to lose by risking the longterm adverse consequences of SCT. In a previous study, Schulz et al. found that intensive chemotherapy plus continuous IM improved survival rate for children and adolescents, with minimal toxicities [30]. And the 3-year EFS was not significantly different for the patients receiving chemotherapy/IM alone compared to those proceeding to sibling donor SCT $(88 \% \pm 11 \%$ vs. $57 \% \pm 22 \%)$. This study suggested the outcomes were not superior with allo-SCT compared with intensive chemotherapy plus IM for a subgroup of younger patients. Recently, Santhosh et al. also evaluated the feasibility of combining IM with a pediatric-based regimen (a modified version of the Dana Farber Cancer Institute protocol) for young adults with $\mathrm{Ph}+\mathrm{ALL}$, in whom the complete response rate was $94 \%$. Of 16 patients who underwent allo-SCT in CR1, six died of non-relapse complications. Based on an intention-to-treat and time-to-donor identification analysis, they did not find any significant difference in either OS or EFS between transplanted and nontransplanted patients [31].

Nevertheless, interpretation of these findings is limited by the small patient numbers and the relative short followup. Thus, it is difficult to answer whether IM/intensive chemotherapy could replace allo-HSCT for younger patients with $\mathrm{Ph}+\mathrm{ALL}$. However, these provocative data open the way for further discussion. Future studies will focus on development of independent prognostic algorism, such as MRD at relevant time-points, to identify a subgroup of good risk younger patients, eligible for receiving treatment with chemotherapy and TKI only, and accordingly sparing SCT.

\section{Imatinib-based therapy in elderly patients}

$\mathrm{Ph}+\mathrm{ALL}$ accounts for $40-50 \%$ of ALL in patients over 50 years, many of whom cannot tolerate intensive chemotherapy and are not eligible for SCT. The question of whether minimization of therapy-related toxicity by combining TKIs with less intensive chemotherapy yielded equivalent results were proposed in this subgroup of patients. Several studies showed IM combined with minimal chemotherapy was able to yield a higher $C R$ rate and fewer deaths without major toxicity in elderly patients than observed in historical controls. However, a main problem of this less intensive approach is the very high relapse rate, yielding an OS probability of less than $20 \%$ in the studies with long-term follow-up [32]. Dasatinib is a dual BCR-ABL and Src kinase inhibitor with approximately 325-fold greater activity than IM against BCR-ABL, and with activity against most mutations resistant to IM, with the exception of T315I, but to date, it is still unknown whether dasatinib therapy is superior to IM in terms of preventing relapse or inducing longer EFS. Now, the European Working Group on Adult ALL (EWALL) disclosed the final results of the combination of dasatinib and a low Intensity chemotherapy (vincristine and dexamethasone) for first-Line treatment in patients with de novo $\mathrm{Ph}+\mathrm{ALL}$ aged $>55$ years [33]. This regimen was followed by chemotherapy and dasatinib interspersed between the therapeutic cycles. Of the 71 subjects, 94\% achieved a CR. At 3 years, relapse free (RFS) and overall survival (OS) were estimated as $42.7 \%$ and $44.7 \%$, respectively. 29 patients relapsed after a median of 9 months. Most relapses were associated with the T315I mutation. And the presence of abnormalities additional to $\mathrm{t}(9 ; 22)$ were associated with a worse RFS. To some extent, the 3 -year OS at $44.7 \%$ for elderly patients is quite encouraging, a result in the range of reported survival in younger adults. This study also identified a subgroup of elderly patients with poor prognosis, in whom reduced intensity conditioning (RIC) or non-myeloablative HSCT will be considered to perform as the consolidation therapy. Other studies incorporated nilotinib or interferon to the induction or consolidation therapy and tried to determine whether these new regimen would improve the results for the elderly, without increasing the toxicity. An Italian trial enrolled $39 \mathrm{Ph}+\mathrm{ALL}$ patients aged $>60$ years or unfit for intensive chemotherapy and SCT [34]. They were treated with two TKIs (nilotinib $400 \mathrm{mg}$ twice daily, and imatinib $300 \mathrm{mg}$ twice daily), alternating for 6 weeks for a minimum of 24 weeks. Overall, one patient was primarily resistant and 13 patients relapsed, and the OS at is $64 \%$ at 2 years. Although in this small cohort of elderly/unfit patients, the rates of relapse and progression were not likely to be different from the rates observed with imatinib alone [35] and dasatinib alone [36], It's important to notice that 
the mutations that occurred at the time of relapse were sensitive to other TKIs (dasatinib and ponatinib).

Interferon as treatment for $\mathrm{Ph}+$ leukemia has attracted renewed interest, fueled by preclinical observations that IFN may recruit dormant CML stem cells into the cell cycle, and enhance their susceptibility to eradication by TKIs. More available clinical data come from the treatment of CML. Recently, an open-label phase II study was designed to investigate the combination of low-dose IFN-alfa with IM as maintenance therapy (MT) in the elderly with $\mathrm{Ph}+\mathrm{ALL}$ patients [37]. Maintenance therapy consisted of IM at a single dose of $600 \mathrm{mg}$ daily, combined with low-dose subcutaneous interferon-alfa-2a starting at $1 \mathrm{MU}$ three times a week with dose escalation to a target dose of $3 \mathrm{MU}$ three times a week. Median overall survival for patients $(n=7)$ receiving IM + IFN-alfa is 5.4 vs. 2.9 years for patients receiving IM alone $(n=12)$. The patients receiving IM + IFN- alfa had a longer median remission duration from start of maintenance (2.2 years), compared with patients receiving IM as MT (0.75 yrs, $\mathrm{p}=0.07)$. The lack of relationship between number of consolidation cycles and remission duration suggests IM + IFN-a MT may be effective even if started earlier during front-line therapy. Evaluation of the more potent 2nd generation TKI in combination with IFNalfa for $\mathrm{Ph}+\mathrm{ALL}$ is warranted in future.

\section{Administration of TKI after SCT}

Minimal residual disease after allo-SCT for Ph + ALL is predictive of relapse. Imatinib administration subsequent to SCT may prevent relapse, but to date there is no largescale prospective randomized control trial to provide sufficient evidence to conclude that IM or other TKIs should be given to all patients after SCT, even though small studies suggested efficacy [38,39]. A single center study from the University of Minnesota showed a trend toward improved outcome in patients who could be treated with IM in the pre- and post-transplant period following myeloablative conditioning [40]. Ram et al. also reported that IM given for a median duration of 1 year after RICSCT had good tolerability and was associated with an improved outcome, although the effect on relapse was not statistically significant [41]. In a Chinese study, IM treatment was scheduled for 3-12 months after SCT, until BCR-ABL transcript levels were negative at least for 3 consecutive tests or molecular remission was sustained for at least 3 months. It was proven that administration of IM after SCT could reduce the 5-year relapse rate (IM group vs. non-IM group: $10.2 \%$ vs. $33.1 \%, \mathrm{p}=0.016$ ), and prolong the 5 -year DFS. (IM group vs. non-IM group: $81.5 \%$ vs. $33.5 \%, p=0.000$ ) [38]. Similarly in a Japanese study, IM after allo-SCT also had a favorable impact on outcome [42].
The optimal time for initiating IM treatment following SCT is not well established. The CSTIBES02 trial reported that IM was poorly tolerated following myeloablative SCT: only $62 \%$ were able to start at a median of 3.9 months after SCT, and many patients required discontinuation or dose reduction due to complications such as GVHD [24]. The GMALL study compared the tolerability and efficacy of post-transplant IM administered either prophylactically (to begin at 3 months after SCT) or following any BCR$\mathrm{ABL}$ reappearance. No significant difference in outcome was observed between prophylactical IM or MRD-triggered IM after SCT (5-year OS 82\% vs. 78\%, respectively). However, more than half of enrolled patients discontinued IM in both groups, predominantly owing to gastrointestinal toxicities, indicating poor tolerance of IM when given early after allo-SCT [43]. In a recent study, postSCT IM therapy was initiated if patient neutrophil counts were $>1.0 \times 10^{9} / \mathrm{L}$ and platelet counts were $>50.0 \times 10^{9} / \mathrm{L}$, or if they displayed either elevated BCR-ABL transcript levels in two consecutive tests, or a BCR-ABL transcript level $\geq 10^{-2}$ after initial engraftment [38]. In this design, interruptions of IM therapy due to adverse events (AEs) were relatively lower. Thus, careful consideration should be given as to when to start IM, based on patient BCRABL transcript levels, while concurrently taking into account the clinical conditions of individual patients (including engraftment and GVHD).

Experience on the use of dasatinib after HSCT is very limited. A study by Caocci and colleagues suggested that administration of dasatinib 120 days after SCT is highly effective in preventing $\mathrm{Ph}+\mathrm{ALL}$ relapse after both autoand allo-SCT [44]. However, another preliminary data from Taiwan could not fully support this conclusion, and extramedullary relapse could be problematic despite provision of both allo-SCT and dasatinib [45]. Prospective and randomized studies for indentifying the appropriate TKI scheme in Ph + ALL after SCT are urgently needed.

\section{Future treatment to overcome TKI resistance}

Despite high remission rate induced by TKI-containing regimens, fewer than $50 \%$ of these patients sustain molecular remission after initial therapy, and overt clinical relapses are frequent, indicating that TKI resistance is a substantial obstacle in Ph + ALL. The emergence of BCR$\mathrm{ABL}$ mutations is the most important mechanism of resistance to TKI. Mutations can occur within the A (activation)-loop, the $\mathrm{P}$ (ATP-binding)-loop region or at the so-called "gatekeeper" residue, threonine 315. Given that the prognosis of patients with Ph + ALL with T315I mutation is poor, many new agents have been clinically investigated in the setting of T315I and other mutations. Ponatinib is a pan-BCR-ABL inhibitor with activity against all IM-resistant mutants, including the T315I mutation. Ninety four patients with CML lymphoid blast phase or 
$\mathrm{Ph}+\mathrm{ALL}$ were included in the pivotal phase 2 study, who were resistant or intolerant to other TKIs [46]. With a short median follow up of 2 months, the major hematologic response were $37 \%$ and $27 \%$, in patients with resistance/intolerance to prior TKI and those with T315I mutation, respectively. Treatment with ponatinib was generally well tolerated, and thrombocytopenia and neutropenia were the most common grade 3 or more AEs. Thus, ponatinib combined with chemotherapy is a promising approach to overcome TKI resistance. Other new drugs such as Aurora kinases (AK) inhibitors [47] and DCC-2036 [48] have recently entered preclinical or clinical testing, but more mature data are required.

\section{New treatment approaches for $\mathrm{Ph}$-negative acute lymphoblastic leukemia}

Although cure rates in pediatric ALL are now around $90 \%$, there is still room for improvement in the management of adult patients with $\mathrm{Ph}$ - ALL, where little progress has been made over the past two decades and long-term cure rates usually do not exceed $40 \%$, even with allo-SCT [49]. Given the disappointing outcomes, there is a critical need for developing new approaches to treating adults with this disease, including the use of "pediatric inspired" regimens and incorporation of novel targeted agents alone or in combination with other chemotherapeutic drugs.

\section{Application of pediatric inspired regimens to young adults}

One of promising approaches in treating young patients with Ph- ALL is adopting pediatric protocols - the so called "pediatric inspired" regimens, especially for those adolescent and young adult (AYA) aged 15 to 39 years. Retrospective studies have shown that AYA with ALL treated with pediatric-inspired regimens have better outcomes than similarly aged patients with adult protocols, and improved the event-free survival rate of newly diagnosed Ph- ALL to $60 \%$ or higher [50]. This compared to $35 \%-40 \%$ for historical controls and without additional benefit of SCT. However, prospective studies comparing AYA adopting adult protocols with pediatric protocols are rare. Recently, a Japan adult leukemia study group conducted a phase II multicenter study to determine the outcome of pediatric protocols for AYA with Ph- ALL (Japan Adult Leukemia Study Group (JALSG) ALL202-U study) [51]. In comparison with the former JALSG ALL-97 adult protocol, the pediatric protocols showed an increase in cumulative dose of cyclophosphamide (1.5-fold), vincristine (1.2-fold), L-asparaginase (18-fold) and methotrexate (3.7-fold), respectively. As for the intrathecal chemotherapy, the duration was longer and the frequency was increased from 8 to 15 times. Of the 138 eligible patients, 134 patients (97.1\%) achieved CR. Compared with previous JALSG ALL-97 study, CR rate (97.1\% ALL202, 84\% ALL97; p =0.01), 4-year DFS rate
(71\% ALL202, 46\% ALL97; $\mathrm{p}=0.0001)$ and 4-year OS rate (74\% ALL202, 46\% ALL97; $\mathrm{p}=0.0002$ ) were significantly higher in this pediatric protocols. Studies by groups in other countries also yielded comparable results [52]. Although it is still unknown why treatment with pediatric protocols resulted in improved outcomes, the disparity may be explained by some common features of pediatric treatment strategies, including (1) significantly increasing the non-myelosuppressive agents such as vincristine and steroids, (2) using much higher cumulative doses of asparaginase (ASP) for prolonged asparagine depletion, (3) administering very early and more frequent intrathecal methotrexate together with very high-dose systemic methotrexate, (4) including longer antimetabolite-based maintenance cycles, and finally, (5) patients treated on pediatric protocols are more likely to adhere to cycle start dates and have shorter rest between cycles. Together, these features may contribute to the improved outcomes for young patients treated on pediatric protocols. However, the outcomes for AYAs with ph- ALL still lag significantly behind those achieved in younger children. Thus, challenges for the future include identifying unique aspects of drug pharmacology in young adults to refine dosing schedules, and recognizing additional biologic factors of AYA, with the anticipation that these discoveries will provide new targeted therapeutic opportunities.

\section{Novel and emerging drugs for ph-negative ALL}

Classic treatment regimens using combination chemotherapy are associated with substantial toxicities that limit further dose escalation. Therefore, development of new, targeted and less toxic agents, such as nucleoside analogues and monoclonal antibodies (mAbs), offer promise for improving the outcome of Ph- ALL.

\section{New types of asparaginase}

As mentioned above, young adults with ALL adopted pediatric regimens, with prolonged use of ASP, mostly E. coli, had better outcomes than historically reported. Considering its potential higher toxicity, however, ASP is either not used or given for much shorter duration, particularly in patients aged $>45$ years. Some new types of ASP are emerging. The pegylated E. coli derived form, PEG-ASP, is most commonly used, because it shows less immune response and a prolonged half-life of 5.7 days compared to 1.3 days for native ASP. The incorporation of PEG-ASP in induction and especially during consolidation therapy seems to improve the outcome with a manageable and reversible toxicity [53,54] as shown in several studies. However, clinical hypersensitivity reactions still occur in 10-30\% of patients requiring its discontinuation. Asparaginase Erwinia Chrysanthemi (Erwinaze ${ }^{\mathrm{TM}}$ ) is an L-ASP derived from a different bacterium and is immunologically distinct from the E. coli L-ASP. Plourde 
et al. conducted a compassionate use trial of Erwinaze in 1368 ALL patients with hypersensitivity to native E. coli or PEG-ASP to collect safety information [55]. 77.6\% of patients were able to complete their Erwinaze treatment. Discontinuation due to allergic reaction occurred in $8.8 \%$ and other AEs in $4.7 \%$. The study suggested Erwinaze was well tolerated with no unexpected toxicities identified beyond those associated with L-ASP treatment. In addition to Erwinaze, L-asparaginase-loaded red blood cells $\left(\right.$ GRASPA $^{\circledR}$ ) has been a new available option for ALL population, including older patients with the disease. In a randomized trial from France, the use of GRASPA in refractory or relapsing ALL showed a reduction in the number and severity of allergic reactions and a trend to fewer coagulation disorders [56]. Another phase II dose escalation study aimed at determining optimal dose of GRASPA that could be combined with standard EWALL chemotherapy backbone in patients aged $>55 \mathrm{y}$ with newly diagnosed Ph- ALL [57]. The study indicated that GRASPA at a dose of $100 \mathrm{UI} / \mathrm{kg}$ infused twice during induction cycles, appears to be the best manner with sustained asparagine depletion and a good efficacy/safety profile, and the dose of $100 \mathrm{IU} / \mathrm{kg}$ was associated with median OS of 15.6 months, compared favorably with historical control.

\section{Monoclonal antibodies}

Recently, the development of monoclonal antibodies has provided hope that tumor-targeted therapy would one day play a role in the treatment of ALL with less systemic toxicity profile [58]. To date, the most data are available for anti-CD20 (rituximab), which has been combined with chemotherapy for the treatment of B-lineage ALL or Burkitt lymphoma [59]. In an update of study from M. D. Anderson, 216 pts with Ph- B-lymphoblastic leukemia have been treated with the modified hyperCVAD regimens with or without rituximab [60]. For the younger (age $<60$ years) CD20-positive subset, rates of complete remission duration (CRD) and OS were better with the combination of hyper-CVAD plus rituximab than with hyper-CVAD alone $(69 \% \mathrm{v} 38 \%$; $\mathrm{P}<.001 \%$ and $71 \% \mathrm{v}$ $47 \%, \mathrm{P}=.003)$. However, in contrast to the Burkitt experience, no benefit from the addition of rituximab was noted in elderly patients (age $>=60$ years), in part because of deaths in CR from infections during consolidation. A similar outcome was also observed in CD20+ Ph- B-precursor ALL from the German GMALL $7 / 03$ study [61]. In their study, among patients younger than 55 years, the addition of rituximab was associated with a 5 -year survival rate of $71 \%$ versus $51 \%$ without rituximab. These studies suggest that rituximab added to intensive chemotherapy has improved the outcome for CD20-positive B-lineage ALL, particularly among younger adults. Further investigation will address the role of extended rituximab therapy with attenuated chemotherapy (to reduce risk of infectious complications) in older patients. And studies combining chemotherapy with ofatumumab or with other more potent CD20 monoclonal antibodies such as GA-101 are also warranted [59,62,63].

Another actively investigated MoAb is anti-CD22. Epratuzumab, the "naked" humanized MoAb against CD22, was first studied in children with relapsed ALL showing minimal single-agent activity [64]. For adult patients, a phase II study through the Southwest Oncology Group (SWOG) is ongoing and presenting some findings. They found giving epratuzumab together with cytarabine and clofarabine improving response rate (to 45\%) in patients with relapsed/refractory $(\mathrm{R} / \mathrm{R})$ precursor $\mathrm{B}-\mathrm{ALL}$, and thus warrants further testing [65]. Inotuzumab ozogamicin, a CD22 monoclonal antibody bound to calicheamicin, is also active in ALL. In a phase II study of inotuzumab 1.3 to $1.8 \mathrm{mg} / \mathrm{m}^{2}$ IV once every 3 to 4 weeks in 49 patients with R/R B-lineage ALL, the overall response rate was 57\% and the median survival of all patients was 4.5 months. Given the heavily pretreated patients, the response rate in R/R ALL was promising and twenty-two of the 49 patients were able to proceed to subsequent allo-SCT. The most common adverse effect was liver function abnormalities that were severe in $31 \%$ of the patients [66]. Recently inotuzumab was delivered at smaller doses and a more frequent schedule (inotuzumab weekly, $0.8 \mathrm{mg} / \mathrm{m} 2 \mathrm{D} 1$, $0.5 \mathrm{mg} / \mathrm{m} 2 \mathrm{D} 8$ and $15, \mathrm{q} 3-4$ weeks) than previously studied. The modified schedule appears to be equally effective with response rate of $53 \%$ and median survival of 6.3 months, and it is less toxic than single dose, indicating this weekly schedule might be superior to single dose schedule [67].

Bi-specific MoAbs constitute a new generation of compounds with a promising future. In a recent phase II trial, blinatumomab, a bi-specific MoAb with a CD3-binding site for the T cells and a CD19 site for the target B cells [68], has been highly effective in treating adult Bprecursor ALL in hematological CR but with molecularly persistent or relapsed disease (MRD positive) [69]. More recently, blinatumomab was investigated in adults with active refractory/relapsed ALL. In an ongoing study, 36 adult patients received blinatumomab at three dosing regimens. Twenty six patients $(72 \%)$ achieved a hematological CR or CR with partial hematological recovery, 24 of whom were MRD negative within the first 2 cycles. These results revealed blinatumomab may become the most effective new single targeted agent so far developed for B-lineage ALL. And side effects, including cytokine release syndrome and CNS events were manageable and reversible. As final dose and schedule, $5 \mu \mathrm{g} / \mathrm{m}^{2} /$ day in week 1 and $15 \mu \mathrm{g} / \mathrm{m}^{2} /$ day for week $2-4$ was selected for further investigation based on safety/efficacy considerations [70]. 


\section{Other potential new agents}

In addition to mAbs, other potential new agents are mammalian target of rapamycin (mTOR) inhibitors, JAK inhibitors [71] and the purine analogs. In T-ALL, attention must be paid to the novel purine analogs such as clofarabine, forodesine, and, especially, to nelarabine [72]. The latter drug has proven to be active in relapsed/ refractory disease [73], and is being evaluated in combination with hyper-CVAD for newly diagnosed T-ALL patients [74].

\section{Improvement in SCT for ph-negative ALL}

Allogeneic SCT is the most potent postremission antileukemic therapy in ph- adult ALL, with OS rates exceeding 50\%. Several older randomized trials and meta-analyses concluded that high-risk, not standard-risk, patients benefited from allogeneic SCT in CR1 [75]. Modern protocols tend to avoid SCT in standard-risk patients who are confirmed to be MRD-negative given the excellent results of pediatric-based chemotherapy. However, two recent randomized trials from MRC-ECOG and JALSG give an opposite conclusion that the statistically significant survival advantage with allo-SCT appears to be greater for patients with standard-risk rather than high-risk ALL patients, a finding that likely reflects the increased treatmentrelated mortality (TRM) in the high-risk (especially older) patients that negated the GVL effect in these patients $[49,76]$. It is noted that inclusion of the younger patients in the two randomized trials may have biased the results in favor of allo-SCT, and therefore ongoing reassessment of the place of allo-SCT needs to be continued.

The increasing use of unrelated donors, umbilical cord blood (UCB), haploidentical donors, and reduced intensity SCT have expanded the opportunity for more patients to undergo SCT. The OS rate of unrelated donor (URD)SCT are currently close to those for related donors; the higher transplant-related mortality of the former is counterbalanced by the lower relapse rate [77]. Development of high-resolution HLA typing technology will further improve the transplant outcome for URD-SCT. UCB has emerged as a major, untapped source for SCT, providing clinicians and patients with increased choices for alternative donors. The use of less well-matched UCB grafts has yielded equivalent results as $8 / 8$ and 7/8 URD allele-matched grafts, enhancing the appeal of this product [78]. Although haploidentical SCT remains investigational, this approach has shown promise when used in conjunction with high-dose posttransplantation cyclophosphamide in patients with very high-risk ALL who lack an unrelated donor $[79,80]$. Finally, RIC facilitates SCT in elderly patients and those who have comorbid conditions. It is shown that RIC-SCT is associated with comparable donor engraftment rates and lower incidences of TRM, but with higher relapse rates than myeloablation.
Thus, OS rates are similar to myeloablative conditioning. Given the negative inherent patient selection criteria bias, RIC-SCT could actually prove to be superior. Autologous SCT has a low antileukemic effect in adult ALL, but could be active in certain situations such as MRD negativity after consolidation [81].

\section{Conclusions}

Despite outstanding advances in the knowledge of the molecular basis of adult ALL, the treatment of this disease remains challenging. Improvements in the outcome of ALL have been observed in young adults as a result of the use of inspired regimens and the broadening of the number of patients who are eligible for allogeneic SCT, whereas the prognosis of the elderly remains poor. Development of new and less toxic agents provide promise to improve the outcome in adult ALL, such as tyrosine kinase inhibitors in Ph-positive ALL, rituximab in CD20-positive disease, blinatumomab in precursor B-ALL and nelarabine in Tlineage ALL. From the biological prospective, genetic profiling approaches will provide a comprehensive view of the complexity of genetic alterations in ALL. Identifying miRNAs, genes, and pathways relevant for the pathogenesis of the leukemia and the biologic determinants of treatment failure may provide novel insights on novel targets [82]. However, these findings should be brought from bench to bedside for novel targeted therapies.

Competing interests

The authors declare that they have no competing interests.

\section{Authors' contributions}

GW participated in concept design and critically revising the manuscript. YZ participated in data collection and drafting the manuscript. $\mathrm{HH}$ participated in reviewing and revising the manuscript. All authors have read and approved the final manuscript.

Received: 2 May 2013 Accepted: 23 May 2013

Published: 18 June 2013

\section{References}

1. Pui CH, Pei D, Sandlund JT, Ribeiro RC, Rubnitz JE, Raimondi SC, Onciu M, Campana D, Kun LE, Jeha $S$, et al: Long-term results of St Jude total therapy studies 11, 12,13A, 13B, and 14 for childhood acute lymphoblastic leukemia. Leukemia 2010, 24(2):371-382

2. Bassan R: Evolving strategies for the management of high-risk adult acute lymphoblastic leukemia. Haematologica 2005, 90(10):1299.

3. Pullarkat V, Slovak ML, Kopecky KJ, Forman SJ, Appelbaum FR: Impact of cytogenetics on the outcome of adult acute lymphoblastic leukemia: results of Southwest Oncology Group 9400 study. Blood 2008, 111(5):2563-2572

4. Sirop SJ A-KA, Begna K, Gangat N, Letendre L, Porrata LF, et al: Lack of prognostic significance of monosomal karyotype and absolute lymphocyte count at diagnosis in Philadelphia chromosome negative acute lymphoblastic leukemia. Blood (ASH Annual Meeting Abstracts) 2012, 120:1476.

5. Nagafuji K, Miyamoto T, Eto T, Kamimura T, Taniguchi S, Okamura T, Ohtsuka E, Yoshida T, Higuchi M, Yoshimoto G, et al: Monitoring of minimal residual disease (MRD) is useful to predict prognosis of adult patients with Ph-negative ALL: results of a prospective study (ALL MRD2002 Study). J Hematol Oncol 2013, 6:14.

6. Mullighan CG: The molecular genetic makeup of acute lymphoblastic leukemia. Hematology Am Soc Hematol Educ Program 2012, 2012:389-396. 
7. Georgopoulos K, Bigby M, Wang JH, Molnar A, Wu P, Winandy S, Sharpe A: The Ikaros gene is required for the development of all lymphoid lineages. Cell 1994, 79(1):143-156.

8. Mullighan CG, Su X, Zhang J, Radtke I, Phillips LA, Miller CB, Ma J, Liu W Cheng C, Schulman BA, et al: Deletion of IKZF1 and prognosis in acute lymphoblastic leukemia. N Engl J Med 2009, 360(5):470-480.

9. Kuiper RP, Waanders E, van der Velden VH, van Reijmersdal SV, Venkatachalam R, Scheijen B, Sonneveld E, van Dongen JJ, Veerman AJ, van Leeuwen FN, et al: IKZF1 deletions predict relapse in uniformly treated pediatric precursor B-ALL. Leukemia 2010, 24(7):1258-1264.

10. Mullighan CG, Miller CB, Radtke I, Phillips LA, Dalton J, Ma J, White D, Hughes TP, Le Beau MM, Pui CH, et al: BCR-ABL1 lymphoblastic leukaemia is characterized by the deletion of Ikaros. Nature 2008, 453(7191):110-114.

11. Martinelli G, lacobucci I, Storlazzi CT, Vignetti M, Paoloni F, Cilloni D, Soverini S, Vitale A, Chiaretti S, Cimino G, et al: IKZF1 (Ikaros) deletions in BCR-ABL1positive acute lymphoblastic leukemia are associated with short disease-free survival and high rate of cumulative incidence of relapse: a GIMEMA AL WP report. J Clin Onco/ 2009, 27(31):5202-5207.

12. Harvey RC, Mullighan CG, Chen IM, Wharton W, Mikhail FM, Carroll AJ, Kang H, Liu W, Dobbin KK, Smith MA, et al: Rearrangement of CRLF2 is associated with mutation of JAK kinases, alteration of IKZF1, Hispanic/Latino ethnicity, and a poor outcome in pediatric B-progenitor acute lymphoblastic leukemia. Blood 2010, 115(26):5312-5321.

13. Roll JD, Reuther GW: CRLF2 and JAK2 in B-progenitor acute lymphoblastic leukemia: a novel association in oncogenesis. Cancer Res 2010, 70(19):7347-7352.

14. Loh ML HR, Mullighan CG, Linda SB, Devidas M, Borowitz MJ, et al: A BCR$A B L 1-l i k e$ gene expression profile confers a poor prognosis in patients with high-risk acute lymphoblastic leukemia (HR-ALL): a report from Children's Oncology Group (COG) AALL0232. Blood (ASH Annual Meeting Abstracts) 2011, 118:743.

15. lacobucci I, Ferrari A, Lonetti A, Papayannidis C, Paoloni F, Trino S, Storlazzi CT, Ottaviani E, Cattina F, Impera L, et al: CDKN2A/B alterations impair prognosis in adult BCR-ABL1-positive acute lymphoblastic leukemia patients. Clin Cancer Res 2011, 17(23):7413-7423.

16. Hof J, Krentz S, van Schewick C, Korner G, Shalapour S, Rhein P, Karawajew L, Ludwig WD, Seeger K, Henze G, et al: Mutations and deletions of the TP53 gene predict nonresponse to treatment and poor outcome in first relapse of childhood acute lymphoblastic leukemia. J Clin Oncol 2011, 29(23):3185-3193.

17. Mullighan CG, Zhang J, Kasper LH, Lerach S, Payne-Turner D, Phillips LA, Heatley SL, Holmfeldt L, Collins-Underwood JR, Ma J, et al: CREBBP mutations in relapsed acute lymphoblastic leukaemia. Nature 2011, 471(7337):235-239.

18. Jenkinson S, Koo K, Mansour MR, Goulden N, Vora A, Mitchell C, Wade R, Richards S, Hancock J, Moorman AV, et al: Impact of NOTCH1/FBXW7 mutations on outcome in pediatric T-cell acute lymphoblastic leukemia patients treated on the MRC UKALL 2003 trial. Leukemia 2013, 27(1):41-47

19. Malyukova A, Brown S, Papa R, O'Brien R, Giles J, Trahair TN, Dalla Pozza L, Sutton R, Liu T, Haber M, et al: FBXW7 regulates glucocorticoid response in T-cell acute lymphoblastic leukaemia by targeting the glucocorticoid receptor for degradation. Leukemia 2013, 27(5):1053-1062.

20. Palomero T, Sulis ML, Cortina M, Real PJ, Barnes K, Ciofani M, Caparros E, Buteau J, Brown K, Perkins SL, et al: Mutational loss of PTEN induces resistance to NOTCH1 inhibition in T-cell leukemia. Nat Med 2007, 13(10):1203-1210.

21. Trinquand A, Tanguy-Schmidt A, Abdelali RB, Lambert J, Lengline $E$ De Gunzburg N, Payet-Bornet D, Lhermitte L, Mossafa H, Lheritier V, et al: Towards a purely oncogenetic risk classification of adult T-ALL: a GRAALL study. ASH Annual Meeting Abstracts 2012, 120(21):881.

22. Tzoneva G, Perez-Garcia A, Carpenter Z, Khiabanian H, Tosello V, Allegretta M, Paietta E, Racevskis J, Rowe JM, Tallman MS, et al: Activating mutations in the NT5C2 nucleotidase gene drive chemotherapy resistance in relapsed ALL. Nat Med 2013, 19(3):368-371.

23. Faderl S, O'Brien S, Pui CH, Stock W, Wetzler M, Hoelzer D, Kantarijian HM: Adult acute lymphoblastic leukemia: concepts and strategies. Cancer 2010, 116(5):1165-1176

24. Ribera JM, Oriol A, Gonzalez M, Vidriales B, Brunet S, Esteve J, Del Potro E, Rivas C, Moreno MJ, Tormo M, et al: Concurrent intensive chemotherapy and imatinib before and after stem cell transplantation in newly diagnosed Philadelphia chromosome-positive acute lymphoblastic leukemia. Final results of the CSTIBES02 trial. Haematologica 2010, 95(1):87-95.
25. Bassan R, Rossi G, Pogliani EM, Di Bona E, Angelucci E, Cavattoni I, Lambertenghi-Deliliers G, Mannelli F, Levis A, Ciceri F, et al: Chemotherapyphased imatinib pulses improve long-term outcome of adult patients with Philadelphia chromosome-positive acute lymphoblastic leukemia: Northern Italy Leukemia Group protocol 09/00. J Clin Oncol 2010, 28(22):3644-3652.

26. Ravandi F, O'Brien S, Thomas D, Faderl S, Jones D, Garris R, Dara S, Jorgensen J, Kebriaei $P$, Champlin R, et al: First report of phase 2 study of dasatinib with hyper-CVAD for the frontline treatment of patients with Philadelphia chromosome-positive $(\mathrm{Ph}+)$ acute lymphoblastic leukemia. Blood 2010, 116(12):2070-2077.

27. Mizuta S, Matsuo K, Yagasaki F, Yujiri T, Hatta Y, Kimura Y, Ueda Y, Kanamori H, Usui N, Akiyama $H$, et al: Pre-transplant imatinib-based therapy improves the outcome of allogeneic hematopoietic stem cell transplantation for BCR-ABL-positive acute lymphoblastic leukemia. Leukemia 2011, 25(1):41-47.

28. Ribera JM, Garcia O, Montesinos P, Brunet S, Abella E, Barrios M, Gonzalez-Campos J, Bravo P, Amigo ML, Hernandez-Rivas JM: Treatment of young patients with Philadelphia chromosome-positive acute lymphoblastic leukaemia using increased dose of imatinib and deintensified chemotherapy before allogeneic stem cell transplantation. Br J Haematol 2012, 159(1):78-81.

29. Intermesoli TCC, Pogliani EM, Di Bona E, Romani C, Cassibba V, et al: In Philadelphia chromosome-positive acute lymphoblastic leukemia $(\mathrm{Ph}+\mathrm{ALL})$ imatinib (IM) and chemotherapy in combination improve remission rate, stem cell transplantation rate and long-term outcome. Blood (ASH Annual Meeting Abstracts) 2012, 120:662.

30. Schultz KR, Bowman WP, Aledo A, Slayton WB, Sather H, Devidas M, Wang C, Davies SM, Gaynon PS, Trigg M, et al: Improved early event-free survival with imatinib in Philadelphia chromosome-positive acute lymphoblastic leukemia: a children's oncology group study. J Clin Oncol 2009, 27(31):5175-5181.

31. Thyagu S, Minden MD, Gupta V Yee KW, Schimmer AD, Schuh AC, Lipton JH, Messner HA, Xu W, Brandwein JM: Treatment of Philadelphia chromosomepositive acute lymphoblastic leukaemia with imatinib combined with a paediatric-based protocol. Br J Haematol 2012, 158(4):506-514.

32. Ribera JM: Optimal approach to treatment of patients with Philadelphia chromosome-positive acute lymphoblastic leukemia: how to best use all the available tools. Leuk Lymphoma 2013, 54(1):21-27.

33. Rousselot PCM, Huguet F, Lafage M, Leguay T, Salanoubat C, et al: Dasatinib (sprycel $\left.{ }^{\circledR}\right)$ and Low intensity chemotherapy for first-line treatment in patients with De novo Philadelphia positive ALL aged 55 and over: final results of the EWALL-Ph-01 study. Blood (ASH Annual Meeting Abstracts) 2012, 120:666

34. Papayannidis CFP, Piciocchi A, Di Raimondo F, Pizzolo G, Carella AM, et al: Treating $\mathrm{Ph}+$ Acute Lymphoblastic Leukemia (ALL) in the Elderly: The Sequence of Two Tyrosine Kinase Inhibitors (TKI) (Nilotinib and Imatinib) Does Not Prevent Mutations and Relapse. Blood (ASH Annual Meeting Abstracts) 2012 2012, 120:2601.

35. Vignetti M, Fazi P, Cimino G, Martinelli G, Di Raimondo F, Ferrara F, Meloni G, Ambrosetti A, Quarta G, Pagano L, et al: Imatinib plus steroids induces complete remissions and prolonged survival in elderly Philadelphia chromosome-positive patients with acute lymphoblastic leukemia without additional chemotherapy: results of the Gruppo Italiano Malattie Ematologiche dell'Adulto (GIMEMA) LAL0201-B protocol. Blood 2007, 109(9):3676-3678.

36. Foa R, Vitale A, Vignetti M, Meloni G, Guarini A, De Propris MS, Elia L, Paoloni F, Fazi P, Cimino G, et al: Dasatinib as first-line treatment for adult patients with Philadelphia chromosome-positive acute lymphoblastic leukemia. Blood 2011, 118(25):6521-6528.

37. Pfeifer HWS, Binckebanck A, Wassmann B, Käbisch A, Lübbert M, et al: Imatinib (IM) and Interferon-Alpha (IFN-a) Maintenance Therapy Is Associated with Long-Term DFS in a Subset of Elderly Patients with Philadelphia-Positive Acute Lymphoblastic Leukemia (Ph + ALL). Blood (ASH Annual Meeting Abstracts) 2012, 120:1503

38. Chen H, Liu KY, Xu LP, Liu DH, Chen YH, Zhao XY, Han W, Zhang XH, Wang Y, Zhang $Y Y$, et al: Administration of imatinib after allogeneic hematopoietic stem cell transplantation may improve disease-free survival for patients with Philadelphia chromosome-positive acute lymphobla stic leukemia. J Hematol Oncol 2012, 5:29.

39. Farnsworth $P$, Ward $D$, Reddy V: Persistent complete molecular remission after nilotinib and graft-versus-leukemia effect in an acute lymphoblastic 
leukemia patient with cytogenetic relapse after allogeneic stem cell transplantation. Exp Hematol Oncol 2012, 1(1):29.

40. Burke MJ, Trotz B, Luo X, Baker KS, Weisdorf DJ, Wagner JE, Verneris MR: Allo-hematopoietic cell transplantation for Ph chromosome-positive ALL: impact of imatinib on relapse and survival. Bone Marrow Transplant 2009, 43(2):107-113

41. Ram R, Storb R, Sandmaier BM, Maloney DG, Woolfrey A, Flowers ME, Maris MB, Laport GG, Chauncey TR, Lange T, et al: Non-myeloablative conditioning with allogeneic hematopoietic cell transplantation for the treatment of high-risk acute lymphoblastic leukemia. Haematologica 2011, 96(8):1113-1120.

42. Nishiwaki S, Miyamura K, Kato C, Terakura S, Ohashi K, Sakamaki H, Nakao S, Harigae $\mathrm{H}$, Kodera Y: Impact of post-transplant imatinib administration on Philadelphia chromosome-positive acute lymphoblastic leukaemia. Anticancer Res 2010, 30(6):2415-2418.

43. Pfeifer $H$, Wassmann B, Bethge W, Dengler J, Bornhauser M, Stadler M, Beelen D, Vucinic V, Burmeister T, Stelljes M, et al: Randomized comparison of prophylactic and minimal residual disease-triggered imatinib after allogeneic stem cell transplantation for BCR-ABL1 positive acute lymphoblastic leukemia. Leukemia 2013, 27(6):1254-1262.

44. Caocci G, Vacca A, Ledda A, Murgia F, Piras E, Greco M, Arras M, Atzeni S, Littera R, La Nasa G: Prophylactic and preemptive therapy with dasatinib after hematopoietic stem cell transplantation for Philadelphia chromosome-positive acute lymphoblastic leukemia. Biol Blood Marrow Transplant 2012, 18(4):652-654.

45. Teng $\mathrm{CL}$, Yu JT, Chen HC, Hwang WL: Maintenance therapy with dasatinib after allogeneic hematopoietic stem cell transplantation in Philadelphia chromosome-positive acute lymphoblastic leukemia. Ann Hematol 2013 [Epub ahead of print].

46. Cortes JE KD-W, Pinilla-lbarz J, le Coutre PD, Chuah C, Nicolini FE, et al: Initial findings from the PACE trial: a pivotal phase 2 study of ponatinib in patients with CML and $\mathrm{Ph}+\mathrm{ALL}$ resistant or intolerant to dasatinib or nilotinib, or with the T315I mutation. Blood (ASH Annual Meeting Abstracts) 2011, 118:109.

47. Carpinelli P, Moll J: Aurora kinases and their inhibitors: more than one target and one drug. Adv Exp Med Biol 2008, 610:54-73.

48. Cortes JE TM, Kantarijan HM, Smith H, Bixby D, Rafferty U, et al: A Phase 1 Study of DCC-2036, a novel oral inhibitor of BCR-ABL kinase, in patients with Philadelphia chromosome positive (Ph+) leukemias including patients with T315I mutation. Blood (ASH Annual Meeting Abstracts) 2011, 118:601.

49. Goldstone AH, Richards SM, Lazarus HM, Tallman MS, Buck G, Fielding AK, Burnett AK, Chopra R, Wiernik PH, Foroni L, et al: In adults with standardrisk acute lymphoblastic leukemia, the greatest benefit is achieved from a matched sibling allogeneic transplantation in first complete remission, and an autologous transplantation is less effective than conventional consolidation/maintenance chemotherapy in all patients: final results of the International ALL Trial (MRC UKALL XII/ECOG E2993). Blood 2008, 111(4):1827-1833.

50. Huguet F, Leguay T, Raffoux E, Thomas X, Beldjord K, Delabesse E, Chevallier P, Buzyn A, Delannoy A, Chalandon Y, et al: Pediatric-inspired therapy in adults with Philadelphia chromosome-negative acute lymphoblastic leukemia: the GRAALL-2003 study. J Clin Oncol 2009, 27(6):911-918.

51. Sakura THF, Yujiri T, Aoyama Y, Kondo E, Fujimaki K, et al: Outcome of pediatric-type therapy for Philadelphia chromosome-negative Acute Lymphoblastic Leukemia (ALL) in Adolescents and Young Adults (AYA): A Study by the Japan Adult Leukemia Study Group (JALSG ALL202-U study). Blood (ASH Annual Meeting Abstracts) 2012, 120:1464.

52. Ribera JM, Oriol A, Sanz MA, Tormo M, Fernandez-Abellan P, del Potro E, Abella E, Bueno J, Parody R, Bastida P, et al: Comparison of the results of the treatment of adolescents and young adults with standard-risk acute lymphoblastic leukemia with the Programa Espanol de Tratamiento en Hematologia pediatric-based protocol ALL-96. J Clin Oncol 2008, 26(11):1843-1849.

53. Rytting M: Peg-asparaginase for acute lymphoblastic leukemia. Expert Opin Biol Ther 2010, 10(5):833-839.

54. Douer DAl, Lunning MA, Ramezani L, Burke P, Mark L, et al: Pharmacokinetics-Based Modification of Intravenous Pegylated Asparaginase Dosing in the Context of a "Pediatric-inspired" Protocol in Adults with Newly Diagnosed Acute Lymphoblastic Leukemia (ALL). Blood (ASH Annual Meeting Abstracts) 2012, 120:1495

55. Plourde PV JS, Hijiya N, Keller FG, Rheingold SR, Dreyer ZE, et al: L-asparaginase (L-ASP) Related Toxicities with Asparaginase Erwinia Chrysanthemi in a large compassionate use protocol. Blood (ASH Annual Meeting Abstracts) 2012, 120:2568.

56. Domenech C, Thomas X, Chabaud S, Baruchel A, Gueyffier F, Mazingue F, Auvrignon A, Corm S, Dombret H, Chevallier P, et al: I-asparaginase loaded red blood cells in refractory or relapsing acute lymphoblastic leukaemia in children and adults: results of the GRASPALL 2005-01 randomized trial. Br J Haematol 2011, 153(1):58-65.

57. Hunault-Berger MLT, Huquet F, Leprêtre $S$, Deconinck E, Uribe MO, et al: Two Years Follow-up Results of Graspall/Graall-SA2-2008 Study: L-AsparaginaseLoaded Red Blood Cell Combined with Standard EWALL Chemotherapy in Older Patients with Newly Diagnosed Philadelphia Chromosome-Negative Acute Lymphoblastic Leukemia (Ph-ALL). Blood (ASH Annual Meeting Abstracts) 2012, 120:1473.

58. Firer M, Gellerman G: Targeted drug delivery for cancer therapy: the other side of antibodies. J Hematol Oncol 2012, 5(1):70.

59. Cang S, Mukhi N, Wang K, Liu D: Novel CD20 monoclonal antibodies for lymphoma therapy. J Hematol Oncol 2012, 5(1):64.

60. Thomas DA KH, Jorgensen JL, Faderl S, Jabbour E, Konopleva M, et al: Outcomes Continue to Be Favorable for De Novo Philadelphia Chromosome Negative B-Lymphoblastic Leukemia (ALL) After Therapy with Hyper-CVAD (with or without Rituximab) Regimen. Blood (ASH Annual Meeting Abstracts) 2012 2012, 120:3572.

61. Hoelzer DHA, Kaul F: Immunochemotherapy with rituximab improves molecular CR rate and outcome in CD20+ B-lineage standard and high risk patients; results of $263 \mathrm{CD} 20+$ patients studied prospectively in GMALL study 07/2003. Blood (ASH Annual Meeting Abstracts) 2010, 116:170.

62. Gupta IV, Jewell RC: Ofatumumab, the first human anti-CD20 monoclonal antibody for the treatment of B cell hematologic malignancies. Ann N Y Acad Sci 2012, 1263:43-56.

63. Robak T: GA-101, a third-generation, humanized and glyco-engineered anti-CD20 mAb for the treatment of B-cell lymphoid malignancies. Curr Opin Investig Drugs 2009, 10(6):588-596.

64. Raetz EA, Cairo MS, Borowitz MJ, Blaney SM, Krailo MD, Leil TA, Reid JM, Goldenberg DM, Wegener WA, Carroll WL, et al: Chemoimmunotherapy reinduction with epratuzumab in children with acute lymphoblastic leukemia in marrow relapse: a Children's Oncology Group Pilot Study. J Clin Oncol 2008, 26(22):3756-3762.

65. Advani AMS, Coutre S, Wood BL, Radich JP, Mims M, et al: Southwest Oncology Group Study S0910: A Phase 2 Trial of Clofarabine/Cytarabine/ Epratuzumab for Relapsed/Refractory Acute Lymphocytic Leukemia. Blood (ASH Annual Meeting Abstracts) 2012, 120:2603.

66. Kantarjian $H$, Thomas D, Jorgensen J, Jabbour E, Kebriaei P, Rytting M, York S, Ravandi F, Kwari M, Faderl S, et al: Inotuzumab ozogamicin, an anti-CD22calecheamicin conjugate, for refractory and relapsed acute lymphocytic leukaemia: a phase 2 study. Lancet Oncol 2012, 13(4):403-411.

67. O'Brien STD, Jorgensen JL, Kebriaei P, Ravandi F, Kwari M, et al: Experience with 2 Dose Schedules of Inotuzumab Ozogamicin, Single Dose, and Weekly, in Refractory-Relapsed Acute Lymphocytic Leukemia (ALL). Blood (ASH Annual Meeting Abstracts) 2012, 120:671.

68. Wang K, Wei G, Liu D: CD19: a biomarker for B cell development, lymphoma diagnosis and therapy. Exp Hematol Oncol 2012, 1(1):36

69. Topp MS, Kufer P, Gokbuget N, Goebeler M, Klinger M, Neumann S, Horst HA, Raff T, Viardot A, Schmid M, et al: Targeted therapy with the T-cell-engaging antibody blinatumomab of chemotherapy-refractory minimal residual disease in B-lineage acute lymphoblastic leukemia patients results in high response rate and prolonged leukemia-free survival. J Clin Oncol 2011, 29(18):2493-2498.

70. Topp MS GN, Zugmaier G, Viardot A, Stelljes M, Neumann S, et al: Anti-CD19 BiTE Blinatumomab Induces High Complete Remission Rate and Prolongs Overall Survival in Adult Patients with Relapsed/Refractory B-Precursor Acute Lymphoblastic Leukemia (ALL). Blood (ASH Annual Meeting Abstracts) 2012, 120:670

71. Furqan M, Mukhi N, Lee B, Liu D: Dysregulation of JAK-STAT pathway in hematological malignancies and JAK inhibitors for clinical application. Biomarker Res 2013, 1(1):5.

72. Trioche $P$, Nelken B, Michel G, Pellier I, Petit A, Bertrand $Y$, Rohrlich P, Schmitt C, Sirvent N, Boutard P, et al: French "real life" experience of clofarabine in children with refractory or relapsed acute lymphoblastic leukaemia. Exp Hematol Oncol 2012, 1(1):39.

73. Gokbuget N, Basara N, Baurmann H, Beck J, Bruggemann M, Diedrich H, Guldenzoph B, Hartung G, Horst HA, Huttmann A, et al: High single-drug 
activity of nelarabine in relapsed T-lymphoblastic leukemia/lymphoma offers curative option with subsequent stem cell transplantation. Blood 2011, 118(13):3504-3511.

74. Jain PKH, Thomas DA, Ravandi F, Kadia TM, Burger JA, et al: Phase II Study of Nelarabine with Hyper-CVAD in Patients with Previously Untreated T Cell Acute Lymphoblastic Leukemia (T-ALL) and Lymphoblastic Lymphoma (LL). Blood (ASH Annual Meeting Abstracts) 2012, 120:1501.

75. Ram R, Gafter-Gvili A, Vidal L, Paul M, Ben-Bassat I, Shpilberg O, Raanani P: Management of adult patients with acute lymphoblastic leukemia in first complete remission: systematic review and meta-analysis. Cancer 2010, 116(14):3447-3457.

76. Kako S, Morita S, Sakamaki H, Ogawa H, Fukuda T, Takahashi S, Kanamori H, Onizuka M, Iwato K, Suzuki R, et al: A decision analysis of allogeneic hematopoietic stem cell transplantation in adult patients with Philadelphia chromosome-negative acute lymphoblastic leukemia in first remission who have an HLA-matched sibling donor. Leukemia 2011, 25(2):259-265

77. Nishiwaki S, Inamoto Y, Sakamaki H, Kurokawa M, lida H, Ogawa H, Fukuda T, Ozawa Y, Kobayashi N, Kasai M, et al: Allogeneic stem cell transplantation for adult Philadelphia chromosome-negative acute lymphocytic leukemia: comparable survival rates but different risk factors between related and unrelated transplantation in first complete remission. Blood 2010, 116(20):4368-4375.

78. Eapen M, Rocha V, Sanz G, Scaradavou A, Zhang MJ, Arcese W, Sirvent A Champlin RE, Chao N, Gee AP, et al: Effect of graft source on unrelated donor haemopoietic stem-cell transplantation in adults with acute leukaemia: a retrospective analysis. Lancet Oncol 2010, 11(7):653-660.

79. Brunstein CG, Fuchs EJ, Carter SL, Karanes C, Costa LJ, Wu J, Devine SM, Wingard JR, Aljitawi OS, Cutler CS, et al: Alternative donor transplantation after reduced intensity conditioning: results of parallel phase 2 trials using partially HLA-mismatched related bone marrow or unrelated double umbilical cord blood grafts. Blood 2011, 118(2):282-288.

80. Lv M, Huang X-J: Allogeneic hematopoietic stem cell transplantation in China: where we are and where to go. J Hematol Oncol 2012, 5(1):10

81. Giebel S, Stella-Holowiecka B, Krawczyk-Kulis M, Gokbuget N, Hoelzer D, Doubek M, Mayer J, Piatkowska-Jakubas B, Skotnicki AB, Dombret H, et al: Status of minimal residual disease determines outcome of autologous hematopoietic SCT in adult ALL. Bone Marrow Transplant 2010, 45(6):1095-1101.

82. Fernando T, Rodriguez-Malave N, Rao D: MicroRNAs in B cell development and malignancy. J Hematol Oncol 2012, 5(1):7.

doi:10.1186/1756-8722-6-40

Cite this article as: Zhao et al:: Novel agents and biomarkers for acute lymphoid leukemia. Journal of Hematology \& Oncology 2013 6:40.

\section{Submit your next manuscript to BioMed Central and take full advantage of:}

- Convenient online submission

- Thorough peer review

- No space constraints or color figure charges

- Immediate publication on acceptance

- Inclusion in PubMed, CAS, Scopus and Google Scholar

- Research which is freely available for redistribution 